\title{
Monetary Policy and Nigeria's Economic Growth.
}

\author{
Adeleke Omolade, Sikiru O.Ashamu and Akinola Morakinyo. \\ School of Accounting, Economics and Finance, University of KwaZulu-Natal, South Africa and \\ Department of Accounting and Finance, Lagos State University, Nigeria
}

\begin{abstract}
The study investigates impact of monetary policy on Nigeria's economic growth between 1970 and 2005. It adopts cointegration and error correction model. The gross domestic product is used as proxy for growth while bank rate, bank credit, monetary policy rate and exchange rate are used as monetary policy variables i.e the independent variables. The result shows that all the variables are integration of order one that is I(1). The cointegration result establishes a long run relationship between growth and monetary policy variables. The long run relationship further indicates that only the exchange rate has significant impact on the growth of Nigeria. However, the error correction model indicates that all the variables can jointly dictate the pace of Nigeria growth in terms maintain economic stability. It is recommended that policy makers to pay more attentions to monetary variables in their attempt to maintain economic stability.
\end{abstract}

Key words: Monetary policy, Growth, Long run relationship, economic stability.

JEL Classification: E52 and E59

\section{Introduction}

The issue of how money and monetary policy influences financial and economic activities has been widely discussed over the years. While it is generally agreed upon that monetary development affects economic and financial performance, others have different views on the extent to which the phenomenon happens.

The growing concern about how effective monetary policy is in achieving its objectives necessitated this study. A lot of questions have been raised regarding the efficacy of monetary policy in solving some macroeconomic problems and achieving economic stability in a developing economy like Nigeria. This might not be unconnected with the fact that developed economies are largely monetized as they are devoid of experiencing the practice of informal financial institutions.

The monetary environment in Nigeria is very unstable in the recent past, with the economy being vulnerable to shocks from volatile commodity price. Our understanding of how these monetary variables (exchange rate, monetary rate, bank rate and credit rate) relate with our economic growth will provide insights to help policy makers in formulating relevant policies and programmes of action to guide against unstable monetary environment in the economy. It will also help in mastering a stable exchange rate so as to reduce the impact of hyper inflation. All these questions and many others will be provided answers by this research work.

Notable researchers in the field of monetary economics in Nigeria have tried through their researches to unravel those inbuilt stabilizers in the economy that are very prone to stimulation of the monetary policy administration. Ajayi (1996) concentrated on the industrial sector of the economy. He studied the effects of the monetary policy on the Nigerian industrial sector. Onyido (1999) in the same vein took another sectorial look at the effectiveness of monetary policy in Nigeria but diverted his attention to the Agricultural sector.

Baljit (2000), was more elaborate. He studied the impact of monetary policy on the developing economy specifically sub-Saharan Africa. All these were just to mention a few of monetary researches on the effectiveness of monetary policy. But a common feature of most of these studies is the fact that they were based on partial assessment. Some of the few that considered the whole economy for example, Baljit (2000) made developing economy his scope without any particular reference to the Nigerian economy. While some are mainly of short run appraisal, the long run effect of monetary policy on the economy was not given adequate attention.

IMF (2000), in one of its publications stressed that ascertaining the extent to which a nation's monetary policy influences her economic growth is vital to the achievement of economic stability in the nation. the extent to which the monetary policy influences economic activities in Nigeria transcends beyond sectorial appraisal only but it involves in-depth look into the long-run effect of Monetary Policy on the economic growth of the Nigerian economy. This research work tends to focus on this and other issues relating to the effectiveness of monetary policy on the Nigerian Economy.

\section{Some Literature}

Erik (1975), in a survey of developing economies conducted a desk research where data on cross countries especially on the sub-sahara Africa emphasized that the narrowness of market and a limited number of financial intermediaries also make discount rate and OMO less effective in LDCsHe concluded therefore that 
selective credit control are perhaps the more effective instrument through which the Central Bank of a developing country can influence the volume and direction of commercial bank lending.

Whitesy and Price (2000), focused on the American economy and studied the impact of monetary policy on commercial bank loans and advances. They also gave what is known as defensive open market operation which are federal purchases and sales of government securities to offset unwarranted effects on bank reserves and due to the nature of the data involved, panel model was used. From these findings, they concluded that monetary policy will be more effective if monetary control work much more through restricting the availability of credit, and through increasing its cost much more through reactions of borrowers. To them it is possible to control spending significantly by limiting the loanable funds without raising significantly market rate of interest.

Ajayi (1996), investigated the impact of monetary policy on the industrial sector of the economy using some variables such as loan-able funds to the industrial sector from the commercial banks, broad money supply, interest rate, inflationary rate, exchange rate, cash reserve and liquidity ratio. All proxies were regressed against the share of industrial sector in GDP and after estimating the parameter estimates of the explanatory variables together with various statistical/econometric tests, the study concluded that monetary policy has not actually impacted significantly on the growth of the industrial sector in Nigeria. However, he attributed the problem of the industrial sector in Nigeria majorly to the neglect that it suffered during the oil boom.

Again, in Onyido (1999), who carried out another sectorial appraisal of monetary policy where focus was placed Agricultural sector. The GDP of Agricultural sector was the dependent variable while he made use of similar explanatory variables to that of Ajayi with the exclusion of liquidity ratio but replaced it with Bank rate which was not involved in Ajayi's work, thus making seven explanatory variables. The conclusion from his empirical findings was similar to that of Ajayi as he concluded that implementation and administration of monetary policy in Nigeria have not had any significant impact on the Agricultural sector.

From his findings, Onyido attributed this to lack of enough loanable funds to the sector, high interest rate, diversion of funds made available for the sector to other sectors etc. However, Onyido didn't spare the oilboom period too as a major set back to the growth of the Agricultural sector in Nigeria.

However, Alade and Ajayi (2003), embarked on a pure desk research work and concentrated on the role of monetary policy in making credit available for development process in an economy. Nigerian economy was used as a case study and they assessed critically the supply of and demand for loanable funds and made use of the loanable funds model which represents or postulates that the demand for and supply of credit determines the interest rate in the financial markets.

They concluded that there exists an inverse relationship between the rate of interest and demand for loanable funds while a direct relationship is expected between the rate of interest and supply of loanable funds. They went further to suggest that empirical evidence has highlighted various factors affecting the demand for and supply of credit. These factors include public sector deficit, private/corporate savings, regulatory and monetary policy.

Baljit (2000), undertook a more elaborate view of monetary policy by focusing on the developing economy as a whole, He made use of a very broad explanatory variables which include all the ones in Friedman's Theory of Money Demand i.e special deposit, return on bonds, returns on equity and inflationary rate after applying ordinary least square. He found out that the $\mathrm{R}^{2}$ was very encouraging and many of the parameters in the estimated model fulfilled the Apriori Expectations. Finally, he concluded that monetary policy has significant impact on the growth of Nigerian Economy.

He further emphasized that monetary policy is an important means through which government authorities in a market economy regularly influence the pace and direction of overall economic activity, not only the level of aggregate output and employment but also the general rate at which prices rise or fall.

However, Ojo (1974) was concerned mainly with establishing that in a developing economy like Nigeria characterized by under developed money market and lack of financial assets, the choice facing on individual is more between money and physical asset rather than between money and financial assets. Consequently, he specified and estimated (using the OLS technique) two kinds of relationship (in ling linear form) between money and its determinants. He first specified real money balance as a function of current nominal income and interest rate. Following the significance of interest rate money balance as a function or nominal income and expected rate of inflation. In this framework he adopted the adaptive expectation hypothesis of derive expected rate of inflation that eventually enter the equation for money demand.

His estimated of this equation suggestion that the demand for money is inelastic with respected to income and price change expectation. The coefficient of inflation rate appear with the right (negative) sign and was statistically significant, thus confirming Ojo belief that physical goods are close substitute for money in our type of economy. He however, cautioned that this finding should not stretched too far since with development of the money market financial instrument and financial intermediation, the role of interest rate may become a significant variable in money demand function in Nigeria and hence in the adjustment process. 
Adejugbe (1988) and Audu (1988) in their studies of money demand function in Nigeria similarly adopted the partial adjustment mechanism in obtaining a specification for demand for both narrow and broad real money balances. Both studies specified the equation in long liner form, but the latter study placed more emphasis on the temporal stability question. Current income rate of interest and inflation rate were the argument in their equations.

While Adejugbe carried out his estimation using the Alknes generalized least square procedure, the OLS technique was adopted by Audu covering the period of 1960 to 1987. In testing for stability, the former utilized the Chow test while the latter employed the Gujarati (1970) test. The conclusions reached by Adejugbe were that measured income, rate of investment and logged variables constituted effective determinants of the demand for money.

Ajewole (1989) was mainly concerned with testing the relevance or otherwise of the Mckinnon model of demand for money to Nigeria, from his empirical findings, he concluded inter-alia that real demand for money in Nigeria is considerably influenced by real income and average return on physical assets broad definition of money is more relevant in modeling real money demand when expected or current (actual) income is used a stable demand for money function exist in Nigeria, interest rate does not significantly influenced money demand in Nigeria, even though it is currently signed; and finally, the maximum model of money demand is relevant and applicable to Nigeria.

Finally, from all the empirical studies discussed above, administration of monetary policy was majorly appraised sectorially without consideration for its effects on the economy as a whole. This has prompted this research work.

\section{Methodology}

This aspect of the study explains the model specification, estimating techniques as well as the sources of data.

\section{Model Specification}

With special reference to the Friedman's restatement of the quantity theory of money and the empirical works of Ajayi (1996) and Baljit (2000), where GDP (dependent variable) is expressed as a function of interest rate, Bank Credit, Bank rate, exchange rate, cash reserve and liquidity ratio. The model for this study is specified thus:

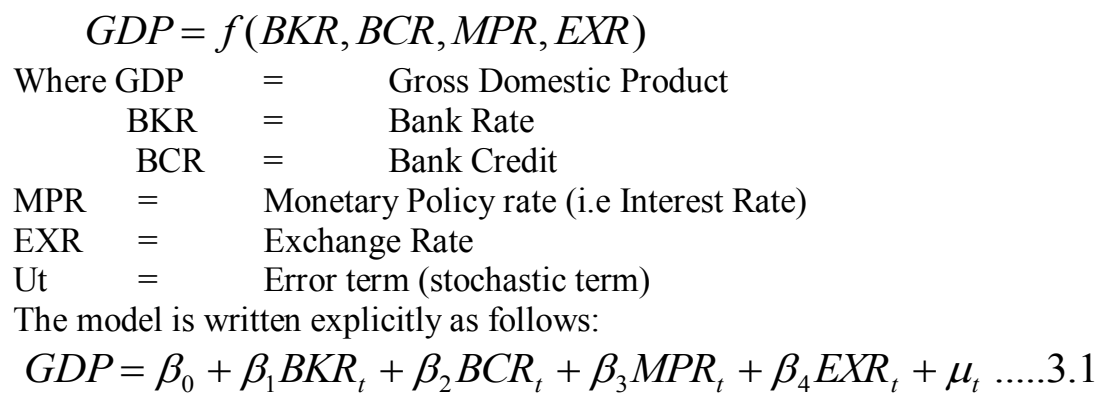

$\alpha_{\mathrm{i}}$ are regression parameters. $\mathrm{i}=1,2,3 \ldots \ldots$.

\section{Estimating Technique}

The estimation procedures employed in this empirical investigation is based on Johansen and Joselius co-integration analysis and the error correction model (ECM).

The choice of this estimation procedure is informed by the need to determine the time series characteristics of the variables that are used in this study. The Johansen co-integration is the statistical equivalence of the economic theoretic notion of stable long-run equilibrium. The existence of the concept among the variables of the model provides somewhat conclusive evidence on the existence of stable equilibrium relationships among them. The process of co-integration is discussed as follows:

\section{Unit Root Test}

Testing for the existence of unit roots is a key pre-occupation in the study of time series models and cointegration. What are unit roots? Let us begin with a definition. A stochastic process with a unit root is itself non-stationary. Another way of looking at it is that testing for the presence of unit roots is equivalent to testing whether a stochastic process is a stationary or non-stationary process. In sum, the presence of a unit root implies that the time series under scrutiny is non-stationary while the absence of a unit root means that the stochastic process is stationary, Maddala (1992) has offered an interesting perspective and interpretation on the testing for unit roots. 
According to him (1992:578), testing for unit roots is a formalization of the Box-Jenkins method of differencing the time series after a visual inspection of the correlogram. No wonder then that testing for units roots plays a central role in the theory and technique of co-integration.

Currently, there are some commonly accepted methods of testing for unit roots. These are the DickeyFuller (DF), Augmented Dickey-Fuller (ADF) test and the Philip Peron (PP) test.

The Augmented Dickey-Fuller (ADF) test is considered superior to the Dickey-Fuller (DF) test because it adjusts appropriately for the occurrence of serial correlation.

$$
X_{t}=b_{0}+b_{1} X_{t-1}+b_{2} X_{t-2}+b_{n} X_{t-n}+U
$$

Where $U$ is a stationary error term. The null hypothesis that $X_{t}$ is non stationary is rejected if $b_{1}$ is significantly negative.

The number of lag (n) of $X_{t}$ is usually chosen to ensure that the regression is approximately white noise. It is simply referred to as the DF test if no such lags are required in which case $b_{i}=0(i=1 \ldots \ldots \ldots \ldots n)$. However, the t-ratio from the regression does not have a limiting normal distribution.

An important assumption of the DF test is that the error term are independently and identically distributed. The ADF test adjust the DF test to take care of possible serial correlation in the error term by adding the lag difference terms of the regressand. Phillip and Perron use non-parametric methods to take care of the serial correlation in the error term without adding lagged difference terms. Since the asymptotic distribution of PP test is the same as the ADF test statistic, the PP test is preferred for this study.

Co-integration is based on the properties of the residuals from regression analysis when the series are individually non stationary.

A series is stationary if it has a constant mean and constant finite variance.

Thus, a time series $X_{t}$ is stationary if its mean $E(X t)$ is independent of time and its variance $E\left\{X_{t}-E\right.$ $\left.\left(X_{t}\right)^{2}\right\}$ is bounded by some finite number and does not vary systematically with time. It tends to return to its mean with the fluctuations around this mean having constant amplitude.

\section{Co-integration and Error Correction Model}

The theory of multivariate co-integration, as propounded and propagated by Johansen and Joselius provides a nexus or connection among integrated processes and the notion of long run equilibrium.

The co integration test commenced with a test for the number of co- integrating relation or rank (r) of $\pi$ using Johansen's maximal Eigenvalue of the stochastic matrix and the likelihood Ratio ( LR) test based on the trace of the stochastic matrix $\pi$ which is the long - run multiplier matrix of $\mathrm{m} \mathrm{x} \mathrm{n}$ that is the matrix of the coefficients. Note that the Eigenvalue of $\pi 1$ are the roots of the kth order characteristic polynomial $\left|\Pi_{1}-\mathrm{vI}\right|$ obtained by solving the characteristic equation

$$
\left|\Pi_{1}-\mathrm{v} I\right|=0
$$

The number of non - zero Eigenvalue is the rank of the matrix $\pi$. Also, the trace statistic suggested by Johansen to determine the co- integration rank in a multivariate model is based on the ordered (estimated) Eigenvalue in the following relation.

$$
\operatorname{Trace}\left(r_{0} / k\right)=-T \sum_{i r=r_{0}+1}^{K} \ln \left(1-\lambda_{i}\right) \text {. }
$$

Where $\quad \lambda i=$ ordered (estimated) Eigenvalue.

This is the relevant test statistic for the null hypothesis $r \leq r_{o}$ against the alternative $r \geq r_{o}+1$ following a sequence (This sequence has been fully discussed under chapter three)

$\Pi$ matrix (the matrix of the coefficient in the VAR models) is a product of two matrices $\alpha$ and $\beta$. Let $Y$ denote an $\mathrm{n} \times 1$ vector of the $\mathrm{I}(1)$ variables the rank of $\pi$ which is $\mathrm{r}$, determines how many linear combination of the variables in the levels are stationary. If $\mathrm{r}=\mathrm{o}$ such that $\pi=0$, none of the linear combination are stationary. $\Pi$ can be factored, that is $\pi=\alpha \beta$. Both $\alpha$ and $\beta$ are $\mathrm{n} \times \mathrm{r}$ matrices. While $\beta$ contains the co-integrating vector (the error - correction mechanism in the system), $\alpha$ is the adjustment parameter.

The second is the maximum Eigenvalue $\left(\lambda_{\max }\right)$ statistic:

$$
\lambda_{\max }=-T \ell n\left(1-\lambda_{r+1}\right)
$$

This test allows for the comparison of a cointegrating rank of $r$ against the alternative of a cointegrating rank of $r+1$. This test may then be repeated for larger values of $r$ until one fails to reject the null hypothesis.

The Johansen representation theorem establishes formally the theoretical basis of error-correction modeling. According to the theorem, if $y_{t}$ and $X_{t}$ are co-integrated, then there is a long run relationship between them. In addition, the theorem proves that the short-run adjustment dynamics can be usefully described by the error correction model (ECM) as stated in the following equation:

$\left.\mathrm{a}(\mathrm{L}) \Delta \mathrm{Y}_{\mathrm{t}}=\mathrm{a}_{\mathrm{o}}-\chi\left(\mathrm{Y}_{\mathrm{t}}-\mathrm{d}_{\mathrm{i}} \mathrm{X}_{\mathrm{t}}\right)+\mathrm{b}(\mathrm{L})\right) \Delta \mathrm{Y}_{\mathrm{t}}+\mathrm{C}(\mathrm{L}) \Sigma_{\mathrm{t}}$ 
In simple terms, the ECM involves using the lagged residual to correct for deviations of actual values from the long run equilibrium values. To fix ideas, consider the equation above and will discover that the residual from that regression is $U_{t}=y_{t}$. BX $X_{t}$ which is $1(0)$, since $y_{t}$ and $X_{t}$ are assumed to be con-integrated. In applied work we require that the coefficient of ECM be significant and negative. Its sign should be negative if it is to play the role of error correction. Specifically, if actual equilibrium value is too high, the error correction term will reduce it while if it is too low, the error correction term will raise it.

\section{Sources Of Data}

In the process of collecting data for this study, all the variables used shall be sourced from the CBN and Nigeria's statistical bulletin (2006) edition.

\section{Descriptive Statistics of Selected Variables}

\section{Results And Discussion}

TABLE 4.1: Descriptive Statistics of Variables

\begin{tabular}{|l|l|l|c|c|}
\hline \multicolumn{1}{|c|}{ Variables } & \multicolumn{1}{|c|}{ Observation } & \multicolumn{1}{c|}{ Mean } & Std Deviation & Probability \\
\hline GDP & 36 & 1125638 & 1874302 & 0.00003 \\
\hline MPR & 36 & 115658 & 6.5428 & 0.462 \\
\hline EXR & 36 & 28.26 & 45.5931 & 0.0008 \\
\hline BKR & 36 & 51.18 & 4.6490 & 0.177 \\
\hline BCR & 36 & 261.42 & 488.75 & 0.00000 \\
\hline
\end{tabular}

Source: Computed from data

We observe from Table 4.1 that all the variables have relatively high variability, which are also significant as shown by the probabilities. Since the variables are not measured in the same unit, therefore the variables are standardized to use for other tests.

\section{Time Series Properties of Variables in the Model.}

The Philip Perron test for unit root was conducted for the variables in the model at both levels and first difference. Accordingly the null hypothesis is that there is a unit root in each variable, that is each variable is non-stationary the rule of thumb is that the null hypothesis of unit root should be accepted if the PP statistic is less negative than the critical value, otherwise, the direction of the alternative hypothesis.

Table 4.2: Philip Peron (PP) Unit Root Test For Selected Series

\begin{tabular}{|c|c|c|c|c|c|c|c|}
\hline & \multicolumn{2}{|c|}{ PP Statistics } & \multicolumn{2}{c|}{ P Values } & \multicolumn{2}{c|}{ Critical Values } & $\begin{array}{c}\text { Order Of } \\
\text { Integration }\end{array}$ \\
\hline Series & Levels & $1^{\text {st }}$ DIff & Levels & !st Diff & $1 \%$ & $5 \%$ & \\
\hline GDP & -2.8894 & -6.3294 & 0.0070 & 0.0000 & -4.2412 & -3.5426 & $\mathrm{I}(1)$ \\
\hline MPR & -4.0405 & 11.3576 & 0.0000 & 0.0000 & -4.2412 & -3.5426 & $\mathrm{I}(1)$ \\
\hline EXR & -0.9446 & -5.5691 & 0.3639 & 0.0000 & -4.2412 & -3.5426 & $\mathrm{I}(1)$ \\
\hline BKR & -2.2182 & -7.4547 & 0.0448 & 0.0000 & -4.2412 & -3.5426 & $\mathrm{I}(1)$ \\
\hline BCR & 10.3775 & -4.6590 & 0.0000 & 0.0000 & -4.2412 & -3.5426 & $\mathrm{I}(1)$ \\
\hline
\end{tabular}

Source: Computed from data

After performing the trend analysis of each series using the line graph, the test in table 4.2 was conducted with the assumption of constant trend in the series. This is so because each of the variables show a relationship with line, that is trended. The result in Table 4.2, therefore indicate that all variables are nonstationery at their levels. I(o). This is so as the their PP statistics are all less negative than the critical values at both the $1 \%$ and $5 \%$ level of significance. This is also confirmed by the high value of Mackinon (1996) associated one sided -P- value in each series at levels. The economic implication of non-stationary series is that of a prolonged or sustained shock if there is any disturbance to the variable. Thus economic growth (GDP), monetary policy rate (MPR), exchange rate (EXR), bank rate of minimum rediscounting rate (BKR) and bank credit (BCR) all exhibit persistent shock.

A further test for unit root to ascertain whether such shock is that of infinity or will die out over time is conducted using the first difference of each variable. The result, also in table 4.2, shows that all the variables are stationary at their first difference and therefore integrated of order one denoted as I(1). Since all series are I(1), a necessary condition for long run equilibrium relationship known as cointegration is met. The result of the Johansen maximum likelihood cointegration test and the associated error correction model are presented.

\section{Cointegration Rank Test On Economic Growth And Monetary Policy}

The test is conducted using the Johanssen cointegration technique since the model is multivariate. The result of the multivariate cointegration is presented in table 4.4 
Monetary Policy And Nigeria's Economic Growth.

Table 4.3: Johansen Multivariate Cointegration Rank Test

\begin{tabular}{|c|c|c|c|c|}
\hline Ho & Ha & Trace Value & Trace test & Trace $(0.95)$ \\
\hline $\mathrm{r}=0$ & $\mathrm{r}=1$ & 0.7791 & $51.91^{*}$ & $68.52^{*}$ \\
\hline $\mathrm{r} \leq 1$ & $\mathrm{r}=2$ & 0.5631 & 23.80 & $27.21^{*}$ \\
\hline $\mathrm{r} \leq 2$ & $\mathrm{r}=3$ & 0.3012 & 11.61 & 29.68 \\
\hline $\mathrm{r} \leq 3$ & $\mathrm{r}=4$ & 0.1930 & $4.32^{*}$ & 15.41 \\
\hline $\mathrm{r} \leq 4$ & $\mathrm{r}=5$ & 0.1194 & 3.76 \\
\hline
\end{tabular}

* Asterisk indicates statistical significance at the $95 \%$ level.

$G D P=3477+2380 M P R+6937 E X R+2551 B K R-4862.9 B C R \quad \ldots .(4.1)$
(506.7)
(573.8)
(1129)
(4797.7)

The LR test of Johansen is based on the trace statistics; look for the number of ranks in multivariate vector. The null hypothesis of no cointegration is rejected at $r=0, r \leq 1$ and $r \leq 4$, since at this levels, the trace test are greater than trace critical values at $5 \%$ level of significance. Thus the test indicates 2 cointegrating equations. The evidence of cointegration indicates that monetary policy will influence economic growth in the long run when it is included in a package of monetary policy variables. The cointegrating equation normalized to economic growth is shown in equation 4.1 .

From the equation, it is clear that in the long-run, monetary policy rate and exchange rate impact positively on economic growth while the bank rate BKR and bank credit are contrary to expectations by impacting inversely on economic growth.

It should be recalled that the bank rate is the lending rate of the bank while the bank credit is the special deposit of bank for lending, equation 4.1 is best integrated using the elasticity coefficients of monetary variables. By using the point elasticity method, the long run monetary policy elasticity of economic growth is estimated at the mean values of variables (see table 4.1). The result of the estimation shows that the elasticity coefficient of monetary policy rate (interest rate) is 0.24 . that mean a unit increase in monetary policy rate will lead to a less than unit increase (0.24) in economic growth in the long run.

Also, the elasticity coefficient of exchange rate (EXR) is 1.74 . That means, a unit increase in exchange rate will lead to more than a unity change in economic growth in the long-run. Economic growth in Nigeria is interest rate inelastic, but exchange rate elastic in the long-run.

The elasticity coefficient of bank rate of minimum rediscount (BKR) and Bank credit (BCR) are 1.16 and 1.13 respectively. This shows that economic growth is both bank rate elastic and bank credit elastic in the long run.

Moreover, the following inferences are drawn from the conintegration rank test.

(i) The trace test supports the evidence of two significant co integrating vector, which implies the existence of a long-run and stable relationship between economic growth, monetary policy rate, exchange rate, bank rate and bank credit.

(ii) The normalized first cointegrating vector on GDP indicates the present positive but relatively inelastic link with monetary policy rate.

(iii) Economic growth shows a negative and relatively elastic relationship with bank rate of minimum rediscount and bank credit respectively.

These findings however are consistent with the findings of Ibi-Ajayi (1996) and Baljit (2000). Since all the variables included in the model are stationary at their first differences, therefore, we estimate the short-run dynamics, the error-correction mechanism (ECM). The results are given in Tables 4.5 and 4.6.

\section{Error Correction Mechanism}

The evidence of cointegration indicates that economic growth will be influenced by monetary policy when it is included in a package of variables. When cointegration exists, the Engel-Granger theorem establishes the encompassing power of ECM over other forms of dynamic specification. The ECM is specified in the parsimonious and over-parametized forms. The difference between the two is simply the choice of long-length included. The results of the two forms are presented in table 4.4 and 4.5 respectively.

TABLE 4.4 ECM OVERPARAMETIZED MODEL

\begin{tabular}{|l|l|l|l|l|}
\hline Variable & Coefficient & Std Error & t-stat & Prob \\
\hline$\Delta$ MPR $(-1)$ & -106392.8 & 32743.2 & -3.2493 & 0.0038 \\
\hline$\Delta$ MPR(-2) & -41052.41 & 50497.01 & -0.8129 & 0.4259 \\
\hline$\Delta$ EXR(-1) & 58992.93 & 23450.7 & 2.516 & 0.0201 \\
\hline$\Delta$ EXR(-2) & 26449.71 & 54566.73 & 0.4847 & 0.6329 \\
\hline$\Delta$ BKR(-1) & -35184.45 & 84758.4 & -0.451 & 0.6823 \\
\hline$\Delta$ BKR(-2) & -37768.32 & 79899.11 & -0.4727 & 06413 \\
\hline$\Delta \mathrm{BCR}(-1)$ & -3535.96 & 2974.3 & -1.1885 & 0.2479 \\
\hline$\Delta \mathrm{BCR}(-2)$ & -4243.96 & 6111.28 & -0.6944 & 0.4950 \\
\hline$\Delta \mathrm{GDP}(-1)$ & 0.0972 & 0.5911 & 0.1645 & 0.8709 \\
\hline
\end{tabular}


Monetary Policy And Nigeria's Economic Growth.

\begin{tabular}{|l|l|l|l|l|}
\hline$\Delta$ GDP(-2) & 0.3758 & 0.2031 & 1.8503 & 0.0784 \\
\hline ECM(-1) & 0.4552 & 0.2263 & -2.0116 & 0.0573 \\
\hline C & 80877.6 & 138260.1 & 0.5849 & 0.5648 \\
\hline
\end{tabular}

$\mathrm{R}^{2}=0.90 ;$ F stat $=17.302 ;$ Prob $($ Fstat $)=0.0000$

TABLE 4.5 ECM PARSIMONIOUS MODEL

\begin{tabular}{|l|l|l|l|l|}
\hline Variable & Coefficient & Std Error & t-stat & Prob \\
\hline$\Delta \mathrm{MPR}(-1)$ & -075771.0 & 20305.2 & -3.7315 & 0.0009 \\
\hline$\Delta \mathrm{EXR}(-1)$ & 88702.78 & 130006.8 & 6.8197 & 0.0000 \\
\hline$\Delta \mathrm{BKR}(-1)$ & 220.34 & 76391.3 & 0.0002 & 0.9977 \\
\hline$\Delta \mathrm{BCR}(-1)$ & -7601.8 & 1446.6 & -5248 & 0.0000 \\
\hline$\Delta \mathrm{GDP}(-1)$ & 0.287 & 0.0909 & 3.159 & 0.0039 \\
\hline $\mathrm{ECM}(-1)$ & -0.136 & 0.1683 & -0.8090 & 0.4256 \\
\hline $\mathrm{C}$ & 53778.9 & 104646.4 & 0.513 & 0.6115 \\
\hline
\end{tabular}

$\mathbf{R}^{2}=\mathbf{0 . 8 6} ;$ F. stat $=29.24$; Prob. of F. stat. $=0.0000$

The overall impact of monetary policy on economic growth in the short-run is very high $(0.86$ in the parsimonious and 0.90 in the overparametized) and negative. However it was shown that the negative impact is restricted to the short-run and tends to disappear in the long-run. From the result, it appears the overparametized model perform better as the ECM (-1) coefficient is greater in absolute terms than the parsimonious. The coefficient is used to determine the speed and direction of adjustant to equilibrium when there is disequilibrium. The ECM coefficient in Table 4.6 is 0.4552 , meaning that approximately 45.5 percent feedback of previous.

The negative sign in the ECM indicates that the adjustant is in the right direction to restore the long-run relationship. The magnitude or speed is higher in the overparametized (45.5\%) than the parsimonious $(13.6 \%)$ higher when the Lag length are increased.

The economic implication of this result is straight forward. It implies that there was a disequilibrium in previous economic growth since ECM coefficient is non - zero in which case, some changes in monetary policy are necessary to restore equilibrium since the coefficient of ECM is less than zero, it also means there is a decline in economic growth and increase in monetary policy is required. Thus (0.4552) ECM so means that about 45.5 percent of such decline in economic growth was restored by the effectiveness of monetary policy.

\section{Conclusion}

The empirical result in this research work has led to some revelations regarding the relationship between the Nigerian Economic growth and monetary policy.

Firstly, we can conclude from the findings in this empirical study that their existed a long-run relationship between Nigerian Economic growth and Monetary Policy during the period under review. Again, it can be deduced from the results that monetary policy rate which is the interest rate does not have any significant impact on the Nigerian economic growth so also the Bank credit and Bank rates. Only the exchange rate is statistically significant at $10 \%$ significant level.

However, despite the fact that the model used passed the overall statistical test of significance, the Rsquare was also high for both the ECM model and the overparametized model of $86 \%$ and $90 \%$ respectively. This shows that in both models, the independent variables account for a substantive change in the dependent variable which tallies with our expectation that these variables should explain extensively changes in GDP over time.

Finally, base on the foregoing, it can be concluded that the impact of the monetary policy on Nigerian economy is increasingly becoming very important and that it is important for policy makers to pay more attentions to monetary variables in their attempt at correcting and guiding the economy.

\section{References}

[1]. Ajayi S.I. and Ojo O.O. (1981). Money and Banking Analysis and Policy in Nigerian Content, George Allen, London.

[2]. Anyawu J.C. (1994), Monetary Policy and Institutions: HybridPublishers Ltd. Pg 86, Pg 140.

[3]. Alade and Ajayi (1997), Money and Banking, An Introduction to Analysis of Policy. John Wileyand Sons, Santa Barbara, 1977 Pg 425 .

[4]. Baljit S. (2000), The General Roles of Monetary Policy in Developing Economy, VIKAS Publishers Hous PVT Ltd.

[5]. Bongton and wicker (1975), Money and Banking ContemporaryPractices, Policies and Issues Business Publications Inc. Texas, IrvinDorsey Ltd. Georgetown, Ontario Pg. 363.

[6]. Federal Republic of Nigeria (1986), Structural Adjustment Programme for Nigeria. July 1986 June 1988. Federal Government Printer Lagos.

[7]. Fescher S. (1986), Issues in Medium-term Economic Adjustment.World Bank Research Observer 1 (163 - 182).

[8]. Fisher (1996), Contemporary Economics, the Dryden Press, Hunsdale, Illinois Pg 143-145.

[9]. Friedman (1970), A Theoretical Framework of Monetary Analysis, Oxford University Press, London.

[10]. Friedman and Schwart (1989), Problems of Monetary Polcies in Underdeveloped Countries, Lavalvan Publishing House P.23. 
[11]. Granger C.W.J. (1986), The Developments in the Study of Cointegrated Variables Oxford Bulleting of Economics and Statistics. Pg. $48,215-228$

[12]. Kent (1960), Monetary Economics: Theory, Policy and Institutions.Hybrid Publishers Ltd. P.86, 140.

[13]. Murky (1977), International Monetary Theory and Policy. London McGraw Hill International Book Coy. Ltd.

[14]. Nwankwo G.O. (1982), BASIC Economics, An introduction for West African Students, Cambridge University Press. P. 23

[15]. Ogwuma. P. (1997), An effective Monetary Policy for Nation Building in (A Publication of the CBN), Volume 21 No 3, July/Sept. 1997.

[16]. Ojo. M. (1992), Monetary Policy in Nigeria in the 1980's and Prospects in the 1990's in the CBN Economic and Financial Review Vol. 3. March 1992. 